\title{
Corrigendum
}

\section{The effects of vitamin and mineral supplementation on symptoms of schizophrenia: a systematic review and meta-analysis - CORRIGENDUM}

\author{
J. Firth, B. Stubbs, J. Sarris, S. Rosenbaum, S. Teasdale, M. Berk and A. R. Yung
}

https://doi.org/10.1017/S0033291717000022 Published online by Cambridge University Press 16 February 2017

An error was included in the recently published article and the correction is listed below.

"Pooled effects showed that vitamin B supplementation (including B6, B8 and B12)..."

should have read:

"Pooled effects showed that vitamin B supplementation (including B6, B9 and B12)..."

The authors would like to apologise for this error.

\section{Reference}

Firth J, Stubbs B, Sarris J, Rosenbaum S, Teasdale S, Berk M, Yung AR (2017). The effects of vitamin and mineral supplementation on symptoms of schizophrenia: a systematic review and meta-analysis. Psychological Medicine 47(9), 1515-1527. doi: 10.1017/S0033291717000022. 